\title{
Monitoring Response of a Few bZip Transcription Factors in Response to Osmotic Stress in Sunflower
}

\author{
Zeinab Esmailzadeh Mianlengeh ${ }^{1}$, Masood Soltani Najafabadi ${ }^{2 *}$, Abbas Saidi ${ }^{1 *}$, Hossein Askari ${ }^{1}$ \\ ${ }^{1}$ Department of Plant Sciences and Biotechnology, Faculty of Life Sciences and Biotechnology, Shahid Beheshti University, G.C, Tehran, \\ Iran. \\ ${ }^{2}$ Genetic Research Department, and Iranian National Plant Gene Bank, Seed and Plant Improvement Institute (SPII), Agricultural \\ Research, Education, and Extension Organization (AREEO), Karaj, Iran
}

\begin{abstract}
"Corresponding authors: Masood Soltani Najafabadi, Genetic Research Department, and Iranian National Plant Gene Bank, Seed and Plant Improvement Institute (SPII), Agricultural Research, Education, and Extension Organization (AREEO), Karaj, Iran Tel/Fax: +98-26-32716923/+98-26-32704851 E-mail: M.soltani@spii.ir, and Abbas Saidi, Department of Plant Sciences and Biotechnology, Faculty of Life Sciences and Biotechnology, Shahid Beheshti University, G.C, Tehran, Iran. Tel/Fax: +98-21-22431964, E-mail: abbas.saidi@gmail.com
\end{abstract}

Received: 20 Dec. 2015; $\quad$ Revised: 20 Sep. 2017; Accepted: 14 Oct. 2017; Published online: 15 May 2018

\begin{abstract}
Background: Sunflower (Helianthus annuus L.) is one of the important vegetable oil supplies in the world and in Iran, as well. It is classified as a drought semi-tolerant crop; however, its yield is adversely affected by drought stress. Understanding the initial events in sensing stress and the related physiologic and biochemical events thereafter, is crucial in designing drought stress breeding programs. Transcription factors are master molecules directly involved in the plant responses under drought stress, from signal perception and transduction to the regulation of physiologic processes.

Objective: The expression pattern of some bZip transcription factors in response to osmotic stress was investigated in sunflower.

Material and Methods: Employing real-time PCR to monitor, the response of $10 \mathrm{bZIP}$ transcription factors was performed under different osmotic stress conditions including $-0.3,0.9$, and $1.2 \mathrm{MPa}$. Whole seedling was sampled at 6,12 , and $24 \mathrm{~h}$ after the osmotic condition application.

Results: Exposure to osmotic potential of $0.9 \mathrm{MPa}$ for $24 \mathrm{~h}$ caused a reduction in the fresh weight of the seedling. Among the evaluated genes, eight genes, $b z-497, b z-502, b z-485, b z-499, b z-492, b z-504, b z-505$, and $b z-509$ appeared as the osmotic stress responsive transcription factor. Changes in the expression of the genes under $0.3 \mathrm{MPa}$ was observed for four genes. Most of the osmotic responsive genes appeared to be up-regulated. Most of responsiveness in the gene expression was happened under 0.9 MPa of the osmotic stress which is corresponding to fresh weight reduction in the seedlings. Among the investigated genes, two genes was identified to have possible roles in sensitive response of sunflower against drought stress. Conclusions: It was a focus to have systemic view on the complex response of the plant to abiotic stress, and avoidance of the single gene analysis. Also, the importance of molecular data in molecular breeding procedures toward achievement of the stress tolerant lines was highlighted.

Keywords: BZip, Osmotic stress, Patchy pattern, Sunflower, Transcription factor
\end{abstract}

\section{Background}

Plants are continuously exposed to the constraints which prevent them from reaching their maximum productivity. Various abiotic stresses, especially drought stress are the most important of these restrictive factors for the crops growth and productivity worldwide. The earth is warming and dry areas are increasing (1), on the other hand, food requirement due to growing population has been a major concern for all nations (2), thus drought stress and developing drought tolerant crops has been considered by researchers to a significant extent. The mechanisms of the response to the drought stress can

Copyright (C) 2017 The Author(s); Published by National Institute of Genetic Engineering and Biotechnology. This is an open access article, distributed under the terms of the Creative Commons Attribution-NonCommercial 4.0 International License (http://creativecommons.org/licenses/ by-nc/4.0/) which permits others to copy and redistribute material just in noncommercial usages, provided the original work is properly cited. 
be evaluated at many different levels, from the whole plant to the molecular level (3). The physiological and molecular aspects of the plant response in drought condition has been broadly been studied (4). Some of these responses include stomatal closure (5), repression of the cell growth and photosynthesis (3), activation of the respiration (6), and accumulation of osmolytes and proteins (7). It is well known that all these changes are due to the changes in the gene expression level (8-10). The extensive investigation on the molecular aspect of the plant responses toward drought and osmotic stress which were gained via high-throughput methods have revealed that two classes of the genes are responsive in this case $(10,11)$ : i. Functional genes which include genes that code proteins which function directly in abiotic stress tolerance such as chaperones, late embryogenesis abundant (LEA) proteins, osmotin, antifreeze proteins, mRNA-binding proteins, key enzymes for osmolyte biosynthesis, water channel proteins, sugar and proline transporters, detoxification enzymes, and various proteases and ii. the regulatory genes (i.e., genes coding for the proteins involved in further regulation of the signal transduction and stressresponsive gene expression). The second category include various transcription factors (TFs), protein kinases, and protein phosphatases.

Transcription factors are master proteins which regulate downstream genes upon recognition of specific sites on their regulatory regions. These low abundant proteins, based on presence of their conserved DNAbinding domains, are classified into several families, including MYB, MYC, WRKY, NAC, bZip, etc (12, 13).

bZip family of TFs contains members which possess two structural features, a basic region which binds to DNA and a leucine zipper dimerization motif. Plant bZip proteins preferentially bind to DNA sequences with an ACGT core. Several evidences indicate the essential role of bZip TFs in various plant developmental processes and adaptation responses against abiotic (14-16) or biotic stresses such as pathogen defense (17), light, seed maturation, and flower development (17). Their overexpression has been shown to have significant effect on the increased osmotic stress (18). As most responses in the plants under various conditions are governed by TFs, monitoring expression behaviors of the TFs could give us a better understanding of the processes running inside plants, which lead to the adaptive responses (4). The best way of gaining this understanding is to have the whole view on the system which is accessible through TF profiling (19). Although the bZIP TF family has been studied well among different plant species
(20-22), a comprehensive profiling for expression of bZIP gene family in response to the osmotic stress is still lacking in several important crop plants, including sunflower. Having information over this can be very helpful for future breeding programs through genetic engineering. The best technology to perform TF profiling was proved to be real-time PCR (23).

Sunflower (Helianthus annuus L.), is an important oil crop that produces a major part of the vegetable oil worldwide. Sunflower seed oil has high nutritional property and is composed of unsaturated fatty acids (90\%) (24). This annual crop is semi-sensitive to drought, however reduction in sunflower yield due to drought stress has been reported worldwide (25, 26). Despite the importance of the crop in supplying edible oil, several factors such as large genome size (3.5 Megabase (27)) and a probably duplicated and complex, $(28,29)$ lead to limited information available at molecular level for the plant.

\section{Objective}

As there was not data available on the functional behavior of bZipTFs under osmotic stress in sunflower and the need for a systemic assessment on its function, in this paper, we triedto take a survey on this subject. To this end, we tried to find data on bZipTFs and measure the responses of the TFs to the different osmotic potential during time courses. The results have indicated the presence of a patchy pattern for expression of the evaluated TFs. This might provide another prove to the multi-level of regulation in response to suboptimal condition.

\section{Materials and Methods}

\subsection{Plant Materials and Stress Treatments}

Seeds of sunflower line AF81-112, a drought sensitive line (30), were supplied from Seed and Plant Improvement Institute, Iran. The seeds were sterilized before and after de-hulling using 50\% sodium hypochlorite for $10 \mathrm{~min}$ followed by $70 \%$ ethanol for $5 \mathrm{~min}$, and germinated on water agar medium for two days under $16 \mathrm{~h}$ of light, $24-25^{\circ} \mathrm{C}$ temperature. After two days, when seedlings were emerged, seedlings were transferred to liquid B5 medium and kept over a shaker-incubator with $60 \mathrm{rpm}$ for five days. Osmotic stress was then applied by adding specific amount of polyethylene glycol6000 (PEG6000) to the B5 medium to provide osmotic potentials of $0,0.3,0.9$ and 1.2 $\mathrm{MPa}$. The amount of PEG to be added to gain the above osmotic potential was calculated using the equation of Michel and Kaufmann (31) and the osmotic potential 
of the media was measured and confirmed using a thermocouple osmometer (Wescor Vapor Pressure Osmometer Model 5100C, Wescor Inc., Logan, Utah, USA) according to the manufacturer's instruction. After six, 12, and $24 \mathrm{~h}$ of stress application, the whole seedlings (including root and shoot) were washed with sterilized water, weighed, and deep frozen in the liquid nitrogen for RNA extraction. For each treatment (i.e., combination of the osmotic potentials and time courses) seven seedlings were considered. The experiment was repeated two more times. As the experiment was conducted in a completely randomized deign with three replications. The fresh weight of samples was subjected to ANOVA and the mean comparisons was done using Duncan's multiple range test.

\subsection{RNA Extraction and $c D N A$ Synthesis}

The seedlings for each treatment were pooled and grinded to a fine powder in the liquid nitrogen. The total RNA was extracted from the samples using RNXplus Kit (CinnaGen) according to the manufacturer's protocol. The integrity and quantity of the extracted RNA was evaluated by loading on $1 \%$ agarose gel and spectrophotometer, respectively. The residuals of the genomic DNA were removed by treating RNA with RNase-free DNaseI (Fermentas, Germany) according to the manufacturer's instructions. The absence of contamination with the genomic DNA was subsequently confirmed by real-time PCR using primer pairs for tubulin and elongation factor 1 (Table 1).

Reverse transcriptase (RT) reactions were performed on $3 \mu \mathrm{g}$ of the total RNA with oligo-dT primer and CinnaGen reverse transcriptase kit, according to the manufacturer's instructions. The efficiency and concentration of the synthesized cDNA was evaluated using Real-Time PCR amplification of the two reference genes encoding tubulin and elongation factor 1 (Table 1).

\subsection{Real-Time PCR Analysis}

PCR reactions were conducted using a StepOne ${ }^{\mathrm{TM}}$ Real-Time PCR system (Applied Biosystems), employing SYBR Green to monitor dsDNA synthesis. Reactions with a final volume of $10 \mu$ Lcontained $1 \mu \mathrm{L}$ of template (cDNA or total RNA), $200 \mathrm{nM}$ of each gene or sequence-specific primer $(4 \mu \mathrm{L}$ of the mixed $0.5 \mathrm{mM}$ forward and reverse primers, respectively), and $5 \mu \mathrm{L}$ of the SYBR Green master mix (Takara, Japan). The following standard thermal profile, as recommended by the manufacturer, was used for all Real-TimePCR reactions: $50{ }^{\circ} \mathrm{C}$ for $2 \mathrm{~min}, 95^{\circ} \mathrm{C}$ for $10 \mathrm{~min}$; 40 cycles of the $95^{\circ} \mathrm{C}$ for $15 \mathrm{~s}$, and $60{ }^{\circ} \mathrm{C}$ for $1 \mathrm{~min}$.
After 40 cycles, the specificity of the amplifications was checked by heating from $60{ }^{\circ} \mathrm{C}$ to $95{ }^{\circ} \mathrm{C}$ with a ramp speed of $1.9^{\circ} \mathrm{C} \mathrm{min}{ }^{-1}$, resulting in melting curves. The threshold cycle, $\mathrm{C}_{\mathrm{T}}$, which is the cycle number at which SYBR Green fluorescence in a PCR reaction reaches to an arbitrarily defined threshold value during the exponential phase of DNA amplification, were used for expression analysis. For each treatment, arithmetic mean of $\mathrm{C}_{\mathrm{T}}$ for Tubulin and Elongation Factor 1 (EF1) genes $\left(\mathrm{C}_{\mathrm{TM}}\right)$ was used for normalization of all $\mathrm{C}_{\mathrm{T}}$ for genes $\left(\mathrm{C}_{\mathrm{Tg}}\right)$ so that $\Delta \mathrm{CT}=\mathrm{C}_{\mathrm{Tg}}-\mathrm{C}_{\mathrm{TM}}$. For comparative expression analysis, $2^{-\Delta \Delta C T}$ method (32) was used, where $\Delta \Delta \mathrm{CT}$ is subtraction of $\Delta \mathrm{CT}$ for stress condition from $\Delta \mathrm{CT}$ for control condition. The $2^{-\Delta \Delta \mathrm{CT}}$ was considered as fold change (FC).

The pattern of gene expression was obtained on $\log _{2} \mathrm{FC}$ of all genes using Multiple Experiment Viewer $(\mathrm{MeV})$ software version 4.1.10. In this analysis Hierarchical Clustering (HCL) was performed on both treatments and genes using average linkage method and Manhattan distance.

\subsection{Bioinformatics Analysis}

The partial genomic and proteins sequences of TFs family bZip were iterated from sunflower TFs site (http://planttfdb_v1.cbi.pku.edu.cn:9010/web/index. php?sp=ha). As the sequences were not completed, we first tried to find ORF sequences which their translation were more closer to the partial protein sequences presented in the site. To confirm that the sequences belong to bZip family, the protein sequences were then blasted (33) against plant database (NCBI, http://www. ncbi.nlm.nih.gov/). In order to design specific primers for each member of the bZip family, the bZip domain of the proteins were identified using tools in Prositeexpasy site (http://prosite.expasy.org/). The primers for realtime PCR were designed based on the non-conserved sequence of the genes using Oligo 7 software (online accessibility). The criteria for primer designing were: predicted melting temperatures $(\mathrm{Tm})$ of $58-62{ }^{\circ} \mathrm{C}$, primer lengths of 19-25 nucleotides, guanine-cytosine (CG) percent of 45-55\%, and PCR amplicon lengths of 60-150 base pairs (bp).The primer sequences and their characteristics are presented in Table 1. Primers for the internal control genes including Tubulin and EF1 were selected according to Fernandez et al (2011, (34)), the sequences of which are included in the Table 1.

\section{Results}

\subsection{Stress Experiment}

The increase in the osmotic potential of the media was 
resulted in the decrease in the sunflower seedling fresh weights. However, the decreases were not so steep, but rather a gradual behavior was observed (Fig. 1). For each osmotic potential level, effect of duration of the osmotic potential imposition was not significant. This may indicate that when the seedlings sense a specific ambient osmotic potential, they may modify their internal osmotic statues and/or trigger a chronic osmotic potential adjustment system which prevent desiccation during time.

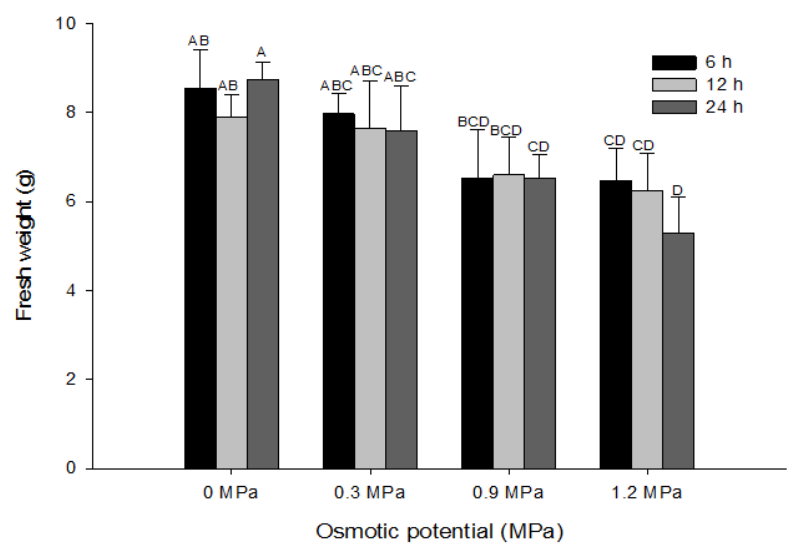

Figure 1. Responses of fresh weight of sunflower inbred line AF81-112 to increases in osmotic potential of the growth media. The seedlings were grown under each osmotic potential for 6,12 , and $24 \mathrm{~h}$. The experiment was repeated three times and average fresh mean over the three biological replications is indicated. Columns having at least one letter in common are not significantly different $(\alpha \leq 0.5)$. Data are represented as means $\pm \mathrm{SD}$.

Under optimum condition ( $0 \mathrm{MPa})$, although nonsignificant, the effect of time on increasing fresh weight (an indication of the growth) was observed (fresh weight at $24 \mathrm{~h}$ vs $12 \mathrm{~h}$ ). Increasing osmotic potential of the medium up to $0.3 \mathrm{MPa}$ did not affect the fresh weights.

The first significant effect of the low osmotic potential on fresh weight as compared to the optimum condition was observed after a prolonged ( $24 \mathrm{~h}$ ) application of 0.9 $\mathrm{MPa}$ osmotic potential. The same effect was observed when seedlings were grown for $24 \mathrm{~h}$ on $1.2 \mathrm{MPa}$ media. In fact in this case, the reduction in fresh weight was significant compared to $0.3 \mathrm{MPa}$ media. In both cases, the effect of osmotic potential of the media on fresh weigh was accelerated by time. This may indicate a probable accumulation effect of damaging factors under hypo-osmotic potentials. This cumulative effect was not detectable under $0.3 \mathrm{MPa}$ potential. Thus, in this experiment, $24 \mathrm{~h}$ incubation on osmotic potential of $0.9 \mathrm{MPa}$ was the start point for seedlings to show their influences by the stress.

\subsection{Bioinformatics Survey}

In the sunflower transcription factor database, gene sequences for 33 accessions have been deposited as bZip transcription factors. Running ORF finding procedure on the gene sequences showed that four genes had no ORF greater than $50 \mathrm{bp}$ in length. Running protein BLAST for the rest of 29 genes, we found that there is less than $25 \%$ homology for 19 genes. As a result, for out of 33 accessions deposited as bZip transcription factor, expression analysis was conducted for 10 genes (Table 1).

\subsection{Expression Analysis}

Melting curve analysis revealed that the primer pairs for each gene were able to amplify a single and therefore specific amplicon (Data are not shown). Also, no track of primer dimer was observed for the primers. Thus, expression analysis using the designed primers was considered to be valid.

In expression analysis, we defined genes to be osmotic stress responsive if their expresion fold change (FC) was greater than 2 or less than 0.5 relative to the control condition. The two limits were considered for up- and down-regulated genes, respectively, and the genes with expression values in between as nonresponsive genes to the osmotic stress. In each osmotic condition, the response of genes were detedted at early (6 h), mid (12 h), and late (24 h) incubation times.

The hierarchical cluster analysis showed the presence of different waves in gene expression among the 10 genes and samples (Fig. 2). Based on the results, gene $b z-504$, $b z-505, b z-492$, and $b z-485$ were appeared as genes with distinct expression patterns over the samples. While genes $b z-503, b z-499$, and $b z-487$ which show nearly the same expression behaviours, were groupped in the same cluster, while, $b z-502, b z-509$, and $b z-497$ genes which showed a different expression pattern appeared as a distinct group. Interestingly, a unique expression pattenr of all genes was observed in $0.9 \mathrm{MPa}$ for $12 \mathrm{~h}$. In this analysis, genes with negative and positive $\log _{2} \mathrm{FC}$ were considered as down-regulated- and up-regulated ones. This analysis which is based on the avarage value of the gene expression gives us an overview on the scattered pattern of the gene expression among the different levles of the stress and time points, and thus, details of information on the behaviour of the genes in not reachable. This could be true, because most of TF gene expressions are suffered from the noises in the expression (35) and so the wide confidence intervals for their expression values make interpretations on the average values as hard and not precise.

The genes of $b z-503, b z-487$, and $b z-499$ were 
Table 1. Primers used for real-time PCR analysis.

\begin{tabular}{|c|c|c|c|c|c|c|}
\hline Code & Gene name* & Primer & 5' to 3 ' & TM $\left({ }^{\circ} \mathrm{C}\right)$ & GC\% & Amplicon size (bp) \\
\hline \multirow{2}{*}{ bz-485: } & \multirow{2}{*}{ РTHa00485.1 } & Forward & AACAACAGCCGCCTCCATAC & 56.2 & 55 & \multirow{2}{*}{64} \\
\hline & & Reverse & CCATAACCACCAGCAACACC & 54.8 & 55 & \\
\hline \multirow{2}{*}{ bz-487 } & \multirow{2}{*}{ РТНа00487.1 } & Forward & GAAATCTCTGGACGAGAAGAAACG & 45.8 & 57.2 & \multirow{2}{*}{80} \\
\hline & & Reverse & TATATCTGCCCGCCCTGATG & 55 & 57 & \\
\hline \multirow{2}{*}{ bz-492 } & \multirow{2}{*}{ РТНа00492.1 } & Forward & GAGCAGTATGGATGGGGAAGTG & 54.6 & 57 & \multirow{2}{*}{80} \\
\hline & & Reverse & GCCGCAGACAGATAACTCAGTG & 54.6 & 56.2 & \\
\hline \multirow{2}{*}{ bz-497 } & \multirow{2}{*}{ РТHa00497.1 } & Forward & CTAAATATGGGGATGGACTTGTGG & 45.8 & 57.3 & \multirow{2}{*}{63} \\
\hline & & Reverse & CGGTCGCATTTTCATGGTTC & 50 & 57.4 & \\
\hline \multirow{2}{*}{ bz-499 } & \multirow{2}{*}{ РТНа00499.1 } & Forward & CGAGCAATGGTTTACTCGATAGC & 47.8 & 56.8 & \multirow{2}{*}{85} \\
\hline & & Reverse & GGTGGGTTACAAGTATGCGTATGG & 50 & 58.2 & \\
\hline \multirow{2}{*}{ bz-502 } & \multirow{2}{*}{ PTHa00502.1 } & Forward & GCAAGAAACGCAGTGGATAGG & 52.4 & 56.1 & \multirow{2}{*}{103} \\
\hline & & Reverse & ACCAGGAACCGTAACCGATG & 55 & 55.9 & \\
\hline \multirow{2}{*}{ bz-503 } & \multirow{2}{*}{ PTHa00503.1 } & Forward & AAGATCACAACCGCCGAATC & 51 & 56.1 & \multirow{2}{*}{147} \\
\hline & & Reverse & AGACATCAGCCTTAGCAGCATC & 50 & 55 & \\
\hline \multirow{2}{*}{ bz-504 } & \multirow{2}{*}{ РTHa00504.1 } & Forward & CGGAAAGAAAAATGTGGATGTG & 40.9 & 55.8 & \multirow{2}{*}{94} \\
\hline & & Reverse & ATGTTGCTGCGGTATCGTTG & 50 & 55.8 & \\
\hline \multirow{2}{*}{ bz-505 } & \multirow{2}{*}{ РTHa00505.1 } & Forward & GGGGATACCGAAGACAAAGC & 55 & 54.8 & \multirow{2}{*}{70} \\
\hline & & Reverse & TGGCATCAGAGACCACAAGC & 55 & 55.7 & \\
\hline \multirow{2}{*}{ bz-509 } & \multirow{2}{*}{ РTHa00509.1 } & Forward & GATACATCGTCGGTTTCGCCTT & 50 & 58.9 & \multirow{2}{*}{64} \\
\hline & & Reverse & CGCTTCTTCTACCCCTTACAATCC & 50 & 58.2 & \\
\hline \multirow[b]{2}{*}{-} & \multirow{2}{*}{ Tubulin } & Forward & CGAGAGCAACATGAATGATCTG & 45.5 & 45.5 & \multirow{2}{*}{93} \\
\hline & & Reverse & ССТСТТССТССТСТТСТТССТСА & 52.2 & 56.8 & \\
\hline & & Forward & AGGCGAGGTATGATGAAATTGTCA & 41.7 & 58.4 & \\
\hline- & $E F 1$ & Reverse & GTCTCTTGGGCTCATTGATTTGGT & 45.8 & 59.2 & 200 \\
\hline
\end{tabular}

*. The accessions are presented in http://planttfdb_v1.cbi.pku.edu.cn:9010/web/index.php?sp=ha.

appeared to be as the osmotic stress non-responsive or noisy genes (Fig 3., also the pannel inside). It means that under different osmotic stress levels and time points, either their FC fall in the non-stress responsive region (FC between 0.5 and 2) or noise in gene expresion, which is shown as the high standard deviation on gene expression, is observed.
There was no detectable expression for $b z-485$ in the control condition and also osmotic stress in all three levels in $6 \mathrm{~h}$ (Fig 4., and the pannel inside). Thus for, the gene is de novo induced upon osmotic stress imposition longer than $6 \mathrm{~h}$. In the $0.3 \mathrm{MPa}$, induction of the gene was observed only at the late time $(24 \mathrm{~h})$. Under osmotic condition of $0.9 \mathrm{MPa}$ and in time points

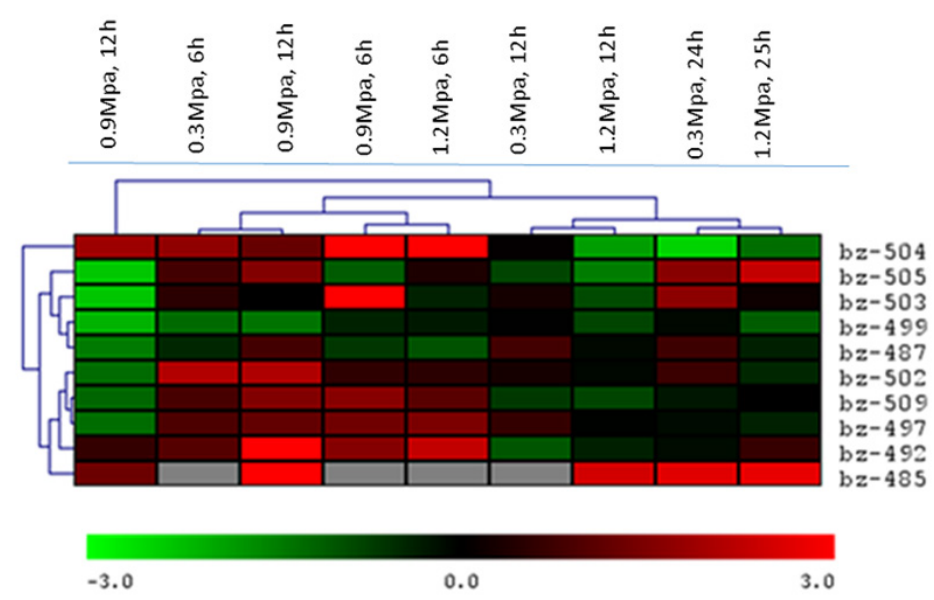

Figure 2. Hierarchical cluster analysis for the relative expression of the 10 genes belonging to the bZip TF of the sunflower seedling. The mean values for the three independent biological replications were subjected to average linkage method and Manhattan distance hierarchical clustering. Sunflower seedlings were subjected to $0.3,0.9$ and $1.2 \mathrm{MPa}$ for $6 \mathrm{~T} 12$, and $24 \mathrm{~h}$. The color saturation reflects the magnitude of the averaged $\log _{2} \mathrm{FC}$. Expression values higher and lower than those of the control are shown in red and green, respectively. The vertical dendrogram (left) indicates the relationship among the TF genes regarding their expression patterns. The horizontal dendrogram (top) indicates the relationship among the treatments with respect to the expression of the bZipTFs. The color scale (bottom) indicates the color assigned to each $\log _{2} \mathrm{FC}$. 

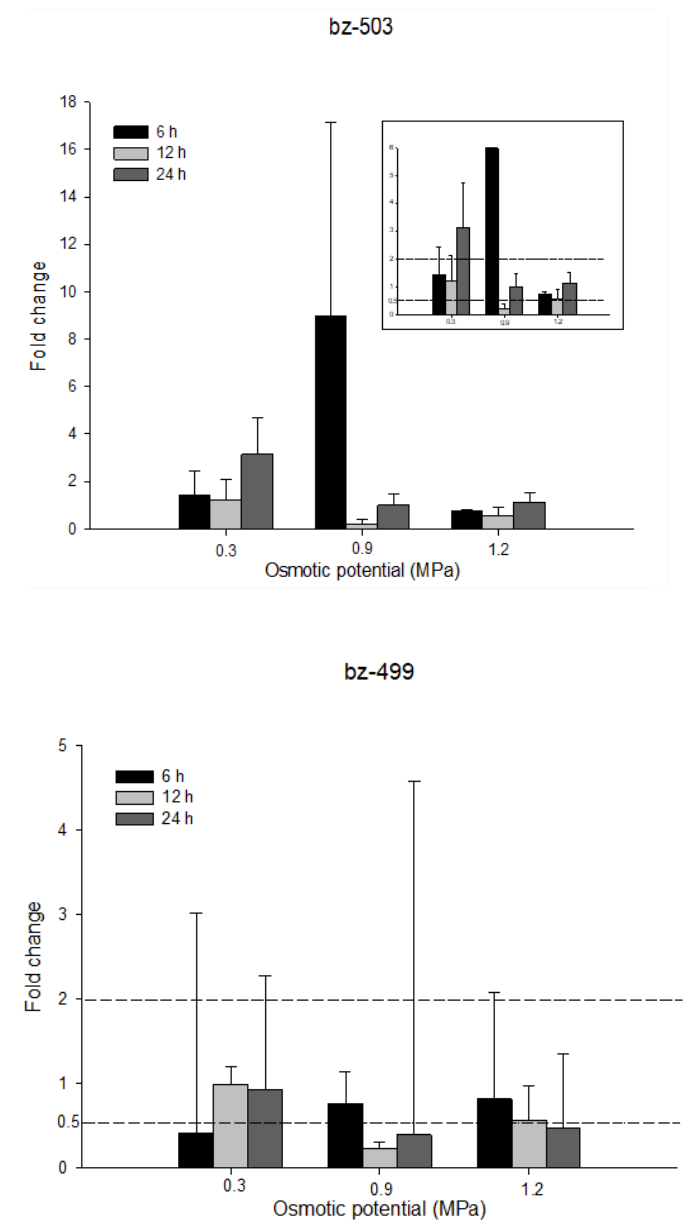

of 12 and $24 \mathrm{~h}$, the gene responsed non-significantly and noisely to the stress, respectedly. In a more severe osmotic stress, $12 \mathrm{~h}$ imposition of the stress resulted in a prominent over expresion of the gene, and a noisy behavour upon longer imposition. It seems that the response of the gene to the reduction of osmotic stress depends on the stress severity and a threshold of the stress signal level required for its induction.

Figure 4. Relative expression of one bZip transcription factor (bz-485) showing de novo induction upon osmotic potential in response to different osmotic potentials $(0.3,0.9$, and 1.2 $\mathrm{MPa}$ ) at various time course of osmotic potential application. Lack of data on some treatments have caused by no gene expression. The time courses included are represented as early (6 h), mid (12 h), and late (24 h) course. For the matter of scaling, inside panel is included. The vertical axis is the relative expression of each gene under the osmotic potentials relative to control condition. The dashed horizontal lines define the threshold for up-regulation (upper limit line) and down-regulation (lower limit line). To show the threshold lines for up- and down-regulation, and because of the scale of $\mathrm{Y}$ axis, an inset panel with increased scale is included. Data are represented as means $\pm \mathrm{SD}$ of three replicates. $b z-487$

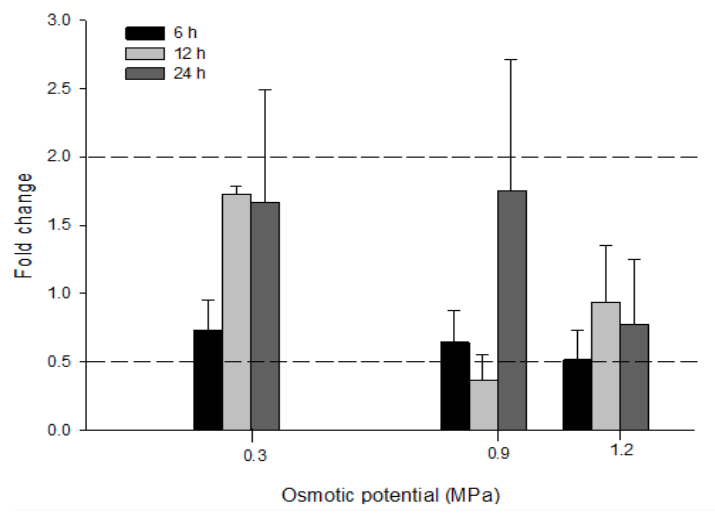

Figure 3. Relative expression of three bZip transcription factors, $b z-503, b z-487$, and $b z-499$ in response to different osmotic potentials $(0.3,0.9$, and $1.2 \mathrm{MPa})$ at various time course of osmotic potential application. $b z-503$ and $b z-487$ did not responded to osmotic potential. Gene $b z-499$ mostly showed noisy pattern, but down-regulated under $0.9 \mathrm{MPa}$ in $12 \mathrm{~h}$. The time courses included are represented as early (6 $\mathrm{h})$, mid (12 h), and late ( $24 \mathrm{~h})$ course. The vertical axis is the relative expression of each gene under the osmotic potentials relative to control condition. The dashed horizontal lines define the threshold for up-regulation (upper limit line) and downregulation (lower limit line). To show the threshold lines for up- and down-regulation, and because of the scale of $\mathrm{Y}$ axis, for gene $b z-503$, an inset panel with increased scale is included. Data are represented as means \pm SD of three replicates.

The genes $b z-492$ and $b z-509$ showed appoximately the same behavour in response to the different osmotic condition as well as time courses (Fig. 5). A bellshaped pattern in the gene expression was observed for the genes. This means gene expression from a non responding (for $b z-509$ for the three time points under $0.3 \mathrm{MPa}$ and $b z-492$ for $6 \mathrm{~h}$ and $24 \mathrm{~h}$ ) or down regulation (for $b z-492$ in $0.3 \mathrm{MPa}$ for $12 \mathrm{~h}$ ) was raised

$b z-485$

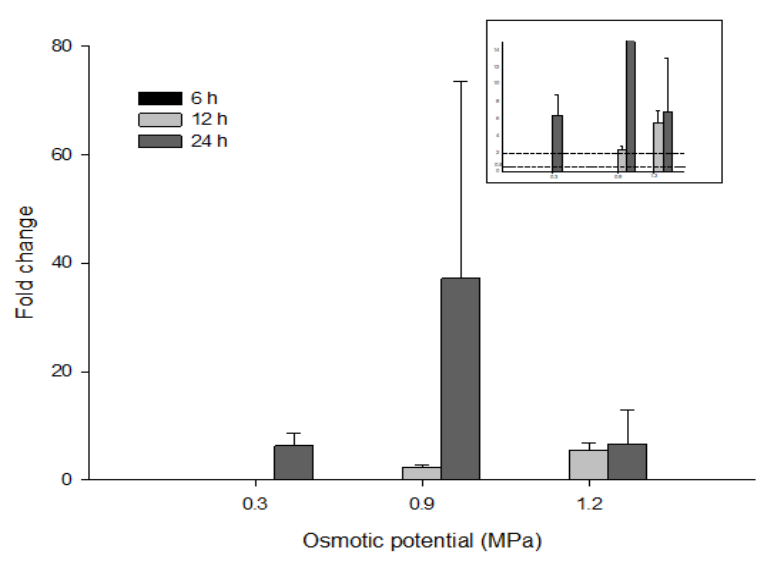


bz-492

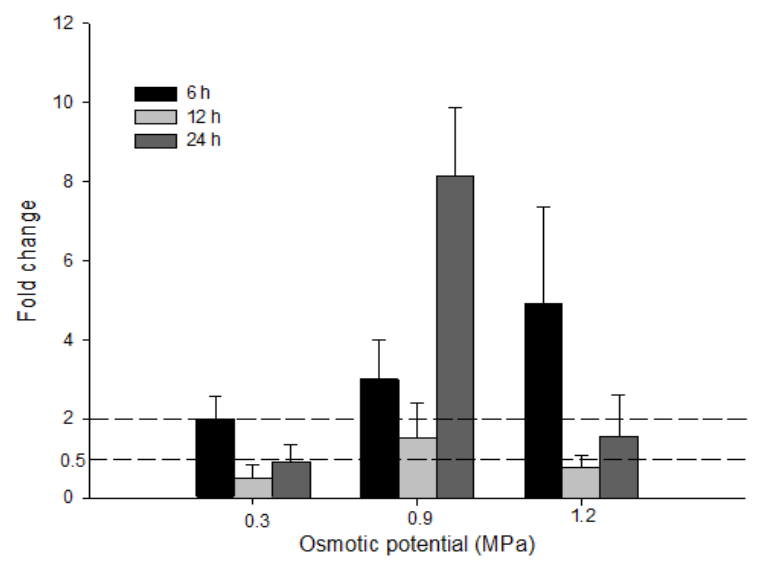

bz-509

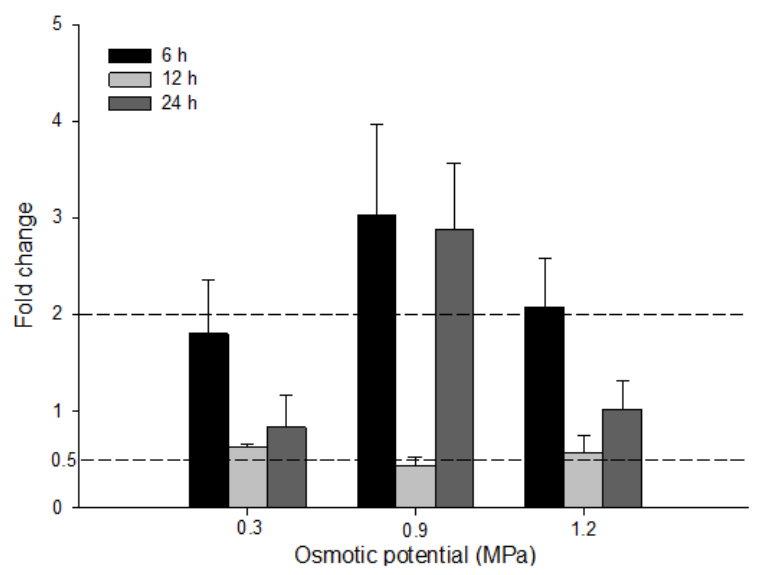

Figure 5. Relative expression of two bZip transcription factors, $b z-492$ and $b z-509$ showing a bell-shaped pattern upon osmotic potential in response to different osmotic potentials $(0.3,0.9$, and $1.2 \mathrm{MPa})$ at various time course of osmotic potential application. The time courses included are represented as early ( $6 \mathrm{~h})$, mid (12 h), and late (24 h) course. The vertical axis is the relative expression of each gene under the osmotic potentials relative to control condition. The dashed horizontal lines define the threshold for up-regulation (upper limit line) and down-regulation (lower limit line). Data are represented as means \pm SD of three replicates.

to up-regulation under $0.9 \mathrm{MPa}$ in the $6 \mathrm{~h}$ and $24 \mathrm{~h}$, but not-responding in $12 \mathrm{~h}$. Their respected $\mathrm{FC}$ was reduced under 1.2 $\mathrm{MPa}$ osmotic potential to non-responding values.

We may propose an abundant and shortage effect model for the signals trigerred by osmotic potential which affect on gene $b z-509$. Under this model, the amont of signal under $0.3 \mathrm{MPa}$, even in $24 \mathrm{~h}$ is not enuoght to triger gene expression. Nevertheless, when severity of the stress reached to $0.9 \mathrm{MPa}$ the amount of signal reached above a threshold and starts to triger gene expression. The product of the gene (i.e., bz-509 protein) may be high enough to prevent more gene expression, and through a negative feedback, could supress its expression per se. When osmotic potential prolonged for more time $(24 \mathrm{~h})$, demands for the bz509 protein trigered its expression again. When no significant FC for $b z-506$ under 1.2 MPa is observed, we may conclude that under severer osmotic stress, plant undertakes another signaling and regulatory pathway.

The $b z-505 \mathrm{TF}$ was appeared to be the late responsive to the three osmotic potentials (Fig. 6). Except for a down-regulation under $0.9 \mathrm{MPa}$ in $12 \mathrm{~h}$, the gene was up-regulated in $24 \mathrm{~h}$ for all the osmotic potentials. The expression pattern for the gene under $0.9 \mathrm{MPa}$ follows a non-linear behavior, that is, in early time point there is not a significant for this TC's relative expression followed by a down-regulation and an up-regulation in late time point, respectively. This behavior could be attributed to the cumulative stress signaling in which in the early time point the amount of signal is not enough to be effective for changing gene expression, but under a prolonged stress condition for (i.e., more than $6 \mathrm{~h}$ ) has negative effect on the gene expression. Nevertheless, upon prolonged stress, the suppressive effect might be withdrawn in a competition between suppressing and inductive effectors, and hence, causing an up-regulation event.

It could be concluded that the production of bz-505 protein may serve as a counter-osmotic or sensor for osmotic severity which is activated upon exceeding of the respected signals above a biological-defined threshold.

$b z-504$ is an early responding gene, which is upregulated in $6 \mathrm{~h}$ and then returned to the same level of expression of the controls under all examined osmotic potentials (Fig 6). Interestingly the up-regulation values showed an exponential behavior as osmotic potential was increased. In the other word, the relative rises in the $b z-504$ transcript were observed to be small in 0.3 and $0.9 \mathrm{MPa}$ followed by a huge increase in 1.2 $\mathrm{MPa}$. Thus, we may conclude that the gene serves as an alarm for the early induction of osmotic stress to the biological system, triggers the responsive downstream mechanisms, and returns back to its background expression thereafter.

$B z-502$ was up-regulated when seedlings were subjected to the $0.3 \mathrm{MPa}$ for $6 \mathrm{~h}$ and returned to the background expression level thereafter (Fig. 7). Nevertheless, without responding to early and middle 
bz-505

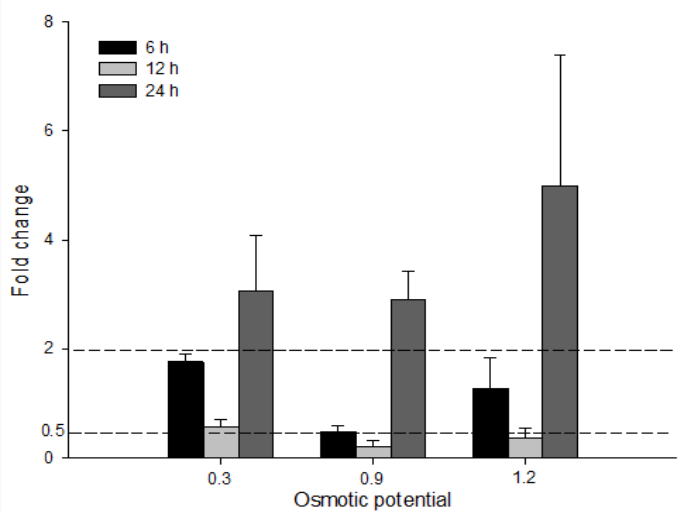

bz-504

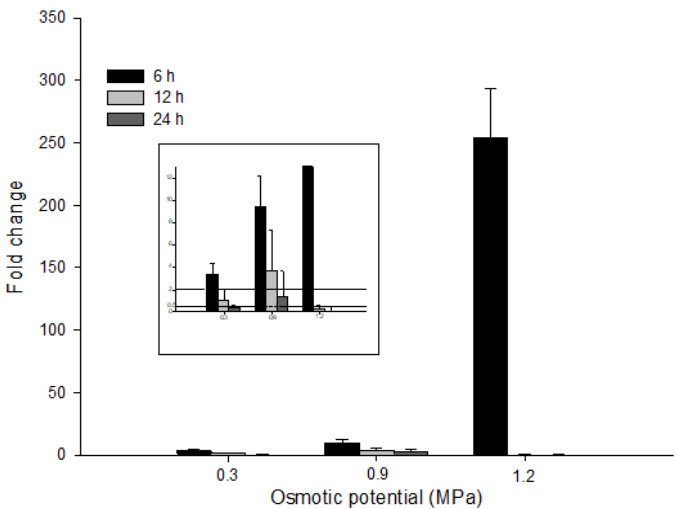

Figure 6. Relative expression of two bZip transcription factors, $b z-505$ with late up-regulation and $b z-504$ with early up-regulating expression patterns in response to different osmotic potentials $(0.3,0.9$, and $1.2 \mathrm{MPa})$ at various time course of osmotic potential application. For the matter of scaling, inside panel in (b) is included. The time courses included are represented as early $(6 \mathrm{~h})$, mid $(12 \mathrm{~h})$, and late $(24 \mathrm{~h})$ course. The vertical axis is the relative expression of each gene under the osmotic potentials relative to control condition. The dashed horizontal lines define the threshold for up-regulation (upper limit line) and down-regulation (lower limit line). To show the threshold lines for up- and down-regulation, and because of the scale of Y axis, for gene $b z-504$, an inset panel with increased scale is included. Data are represented as means \pm SD of three replicates.

bz-502

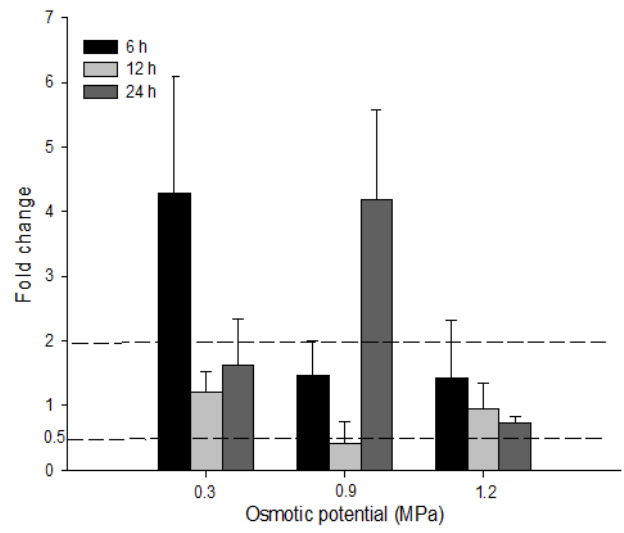

bz-497

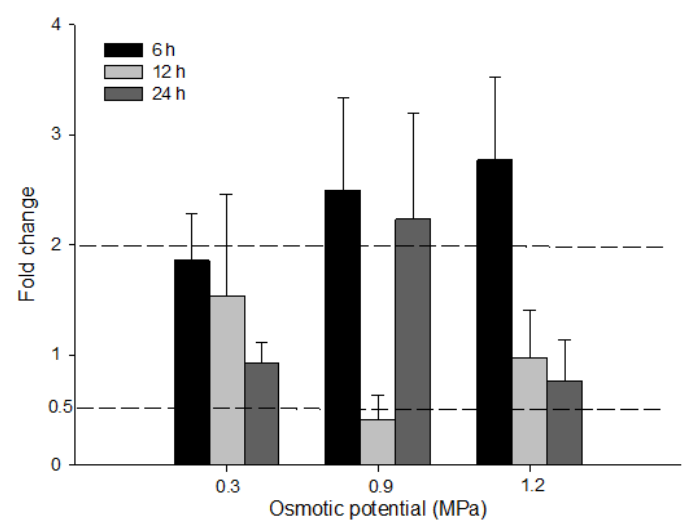

Figure 7. Relative expression of two bZip transcription factors, bz-502 with stress responding behavior only in low stress level $(0.3 \mathrm{MPa})$ and bz-497 with stress responding behavior only in severe stress level (1.2 MPa) in response to different osmotic potentials $(0.3,0.9$, and $1.2 \mathrm{MPa})$ at various time course of osmotic potential application. The time courses included are represented as early $(6 \mathrm{~h})$, mid $(12 \mathrm{~h})$, and late $(24 \mathrm{~h})$ course. The vertical axis is the relative expression of each gene under the osmotic potentials relative to control condition. The dashed horizontal lines define the threshold for up-regulation (upper limit line) and down-regulation (lower limit line). Data are represented as means $\pm \mathrm{SD}$ of three replicates.

time points under $0.9 \mathrm{MPa}$, second rise in the relative expression level was occurred at the late time point (24 h). As well, a more imposition to the osmotic potential (1.2 $\mathrm{MPa})$ had no effect on its relative expression. In fact, this gene seems to be an early responding gene and has a low threshold for induction upon osmotic stress. These characters may represent position of this gene as a beginner in osmotic stress signal perception.
Upon signal perception, a series of signaling events are triggered, and thus no need for further expression of the gene.

The gene $b z-497$, however, showed an opposite response compared to that of $b z-502$ (Fig. 7) which was no prominent relative expression, but rather a noisy feature under 0.3 and $0.9 \mathrm{MPa}$ of the osmotic stress, and only an up-regulation response at early exposure 
(i.e., $6 \mathrm{~h}$ ) under 1.2 $\mathrm{MPa}$.

Bz-499 has mostly shown a noisy pattern (Fig. 3 ), that is among, the gene appeared once as downregulated and in another instance as an up-regulated gene. Nevertheless, the gene was down-regulated under imposition of $0.9 \mathrm{MPa}$ osmotic stress for $12 \mathrm{~h}$.

\section{Discussion}

The osmotic potential of the growth media has significant effects on the reduction of the fresh weight. In this study, sunflower seedling showed a level of tolerance (or buffering) to the increases of the medium osmolarity up to $0.9 \mathrm{MPa}$. Thus, $0.9 \mathrm{MPa}$ could be considered as the threshold for overcoming the tolerance, or attenuating the buffering. So, the seedlings must employ different mechanism in order to cope against increases in the osmotic stress below $0.9 \mathrm{MPa}$. The early tolerance to the increases in the medium's osmotic potential has been reported in Arabidopsis thaliana (36). Therefore, it is a common response in plants to respond with a kind of buffering during the initial phase of stresses. During this phase, stress signal which has been already sensed by the plant is transduced and through activation of complex array of pathways adaptive responses will be initiated $(37,38)$. The growth reduction of sunflower seedlings under osmotic stress can be a result of both meristem growth retardation (39) and wasting metabolic energy for biosynthesis of osmoprotectants $(40,41)$, which are produced in high concentrations and upon osmotic stress $(42,43)$.

Arabidopsis and rice genomes contain 77 and 90 loci, respectively, coding for a large group of bZipTFs (http://plntfdb.bio.uni-potsdam.de/v3.0/), so, it is possible to perform TF profiling over the gene family on the plant under various conditions $(44,45)$. Although genome size of sunflower is estimated to be approximately $3.5 \mathrm{~Gb}$ (27), and not comparable to Arabidopsis thaliana (125 Mb) and Oryza sativa (389 $\mathrm{Mb})(46,47)$, only 33 bZip genes have been predicted in its genome (http://planttfdb_v1.cbi.pku.edu.cn:9010/ web/index.php?sp=ha). As the gene sequences of these 33 genes are not fully presented in the aforementioned database, and number of sequences which met realtime PCR criteria for designing primers (23) were limited, we were able to monitor relative expression level of only 10 members of the gene family. Thus, we employed micro-transcription factor profiling term for cases which a subset member of a TF family was investigated. Nevertheless, updating the database could provide the possibility to monitor expression level of more genes from this TF family.

We were able to observe different patterns of gene expressions among the genes under different osmotic potentials and time courses. Six TFs did not show any changes under the low stress level of $0.3 \mathrm{MPa}$. These observations are in agreement to the behavior of seedling fresh weight under this osmotic potential where no significant reduction in the fresh weight was noticed. As the effect of osmotic potential of 0.3 MPa on seedling growth is negligible, a phenomenon which we call it as seedling buffering, and because of up-regulation of a number of genes in this condition (e $g, b z-505, b z-504, b z-502$, and $b z-485$ ), the genes may be involved in the protection of seedling under the mentioned osmotic potential. Indeed, buffering of seedling to $0.3 \mathrm{MPa}$ might be a result of up-regulation of the mentioned genes in different time points. Certainly, in this buffering, many other TFs might be involved either belonging to this family or the other families, respectively.

Under $0.9 \mathrm{MPa}$ condition a significant reduction in the fresh weight was observed for seedlings experiencing this potential for $24 \mathrm{~h}$ compared to the control condition, which was is concomitant with down-regulation of gene $b z-499$. It is not unlikely that the gene has protective effects on biology of the seedling, and when plants is not able to keep its expression high enough to employ its protective role, fresh weight reduction is observed. Nevertheless, up-regulation of genes $b z-492, b z-509$, $b z-505$, and $b z-504$ might be attributed to either their non-osmotic relevance or suppressing effect of the genes in the protective pathways.

The sever reduction in the fresh weight of seedlings that was observed in $1.2 \mathrm{MPa}$ for $24 \mathrm{~h}$ may draw our attention to the negative role of $b z-504$ on plant protection events that is when stress severity was increased from $0.9 \mathrm{MPa}$ to $1.2 \mathrm{MPa}$ the $b z-505$ relative expression showed an increasing trend. Moreover, the role of $b z-504$ in plant protecting systems is highlighted when its relative expression in early time of stress imposition for the three-osmotic potential is significantly high. The very high relative expression of the gene in the seedlings imposed for $6 \mathrm{~h}$ by $1.2 \mathrm{MPa}$ osmotic stresses, and a deep reduction in the expression during subsequent time points may reveal that the gene belongs to the first line of defense of the seedling against osmotic stresses. This hypothesis gets closer to the reality when we realize that the used sunflower line in this experiment is classified as drought sensitive line.

During the time points, treating of the seedling with $24 \mathrm{~h}$ osmotic stress had significant effects on the seedling which was reflected in reducing the fresh weight. There is an interesting and clear companion between the reduction in the fresh weight and up- 
regulation of bz-505 in $24 \mathrm{~h}$ of stress impositions. Thus, suppressing effect of the gene in breaking of buffering against osmotic stress in sensitive line is proposed. Therefore, it is not unlikely that $b z-505$ might play a more prominent role than other evaluated genes in this study in the adaptation and response of the seedling to the increases in the osmotic potential of the medium.

We made a small scale bZipTF profiling on a drought sensitive line. Although two of the ten evaluated genes did not show any responses to the osmotic stress, there also is not a solid evidence for the linkage of the eight other genes in response to the osmotic adaption responses. When plants are exposed to the abiotic stresses, a plenty of genes appear to become subject of up- or down-regulation. However, not all the deregulated genes (genes which are effected by expression) have a relevant effect in the adaptation to the stresses $(48,49)$. However, this statement is not fully supported for TFs (10), which are low abundant master molecules with prominent effects on all aspect of biology (23). Indeed, their expression is strongly regulated in several levels (50), therefore, they are infrequently expressed as not-relevant genes in specific conditions. Although in this study a link was found between reduction in the fresh weight of the seedling under osmotic stress and the expression behavior of the genes $b z-504$ and $b z-505$, for the other genes there was a lack of clear and straightforward pattern which could be drawn between phenotypic observations and the relative expression of the genes under investigation (patchy behavior of the gene expression (51), (Fig. 2). The reason for this patchy behavior can be explained by the two possibilities: i. small number of genes for analysis. It is possible that the genes under investigation are not the most important genes from this gene family. ii. the presence of a precisely regulated coordination between different components. Under this assumption, to gain a special response, several components such as various TFs are working in concert and theses TFs may insert minor impacts on the whole response. BZip family of TFs contains protein members which their responses in several aspects of plants such as growth and development and stress signaling have been already proved $(15,16)$. So, we may consider different bZipTFs as dispersed pieces of a puzzle, which upon stress, they are brought together to make a whole response at molecular level. This finding one more time highlights the need for having systematics view on interpretation of biological data. This finding, additionally focuses on the requirement of having a systemic view on the complex response of the plant to the abiotic stress. By advancing in the genome information of the sunflower, it is advised to bring more genes form the bZipTFs into account for elucidating more about the molecular aspect of the sunflower response to the osmotic stress. As an applied conclusion, monitoring of the molecular events in response of a drought sensitive sunflower line, rather than a tolerant one, to the osmotic stress can show us the weakness shunts of the lines under stress application. Having the knowledge will help molecular breeding procedures to fortify the weak points toward creation of stress tolerant cultivars in future.

\section{Acknowledgments}

We would like to mention and appreciate lab supports by Mr Esmail Rajaei from Shahid Beheshti University and Ms Neda Iravani, for their kind contribution through progress of the present work.

\section{References}

1. Hanson PJ, Weltzin JF. Drought disturbance from climate change: response of United States forests. Science Total Environ. 2000;262 (3):205-220. doi: 10.1016/S0048-9697(00)00523-4

2. Ahuja I, de Vos RCH, Bones AM, Hall RD. Plant molecular stress responses face climate change. Trend Plant Sci.2010;15 (12):664-674. doi: 10.1016/j.tplants.2010.08.002

3. Chaves MM, Flexas J, Pinheiro C. Photosynthesis under drought and salt stress: regulation mechanisms from whole plant to cell. Ann Bot.2009;103:551-560. doi: 10.1093/aob/mcn125

4. Chaves MM, Maroco JP, Pereira JS. Understanding plant responses to drought - from genes to the whole plant. Func Plant Biol.2003;30 (3):239-264. doi: 10.1071/FP02076

5. Flexas J, Medrano H. Drought inhibition of photosynthesis in C3 Plants: stomatal and non-stomatal limitationsrevisited. Ann Bot.2002;89 (2):18318-9. doi: 10.1093/aob/mcf027

6. Flexas J, Bota J, Galmés J, Medrano H, Ribas-Carbó M. Keeping a positive carbon balance under adverse conditions: responses of photosynthesis and respiration to water stress. Physiol Plant.2006;127 (3):343-352. doi: 10.1111/j.13993054.2006.00621.x

7. Serraj R, Sinclair TR. Osmolyte accumulation: can it really help increase cropyield under drought conditions? Plant Cell Environ.2002;25:333-341. doi: 10.1046/j.13653040.2002.00754.x

8. Fujita Y, Fujita M, Shinozaki K, Yamaguchi-Shinozaki K. ABA-mediated transcriptional regulation in response to osmotic stress in plants. J Plant Res.2011; 124(4):509-525. doi:10.1007/ s10265-011-0412-3

9. Nakashima K, Yamaguchi-Shinozaki K. Regulons involved in osmotic stress-responsive and cold stress-responsive gene expression in plants. Physiol Plant.2005;126 (1):62-71. doi: 10.1111/j.1399-3054.2005.00592.x

10. Shinozaki K, Yamaguchi-Shinozaki K, Seki M. Regulatory network of gene expression in the drought and cold stress responses. Curr Opin Plant Biol.2003;6 (5):410-417. doi: 10.1016/S1369-5266(03)00092-X

11. Rabbani MA, Maruyama K, Abe H, Khan MA, Katsura K, Ito $\mathrm{Y}$, et al. Monitoring expression profiles of rice genes under cold, drought, and high-salinity stresses and abscisic acid application using cDNA microarray and RNA gel-blot analyses. Plant 
Physiol. 2003;133:1755-1767. doi: 10.1104/pp.103.025742

12. Pérez-Rodríguez P, Riaño-Pachón DM, Corrêa LGG, Rensing SA, Kersten B, Mueller-Roeber B. PlnTFDB: updated content and new features of the plant transcription factor database. Nucleic Acid Res.2009;25:1-6. doi: 10.1093/nar/gkp805

13. Riechmann JL, Heard J, Martin G, Reuber L, Jiang C-Z, Keddie J, et al. Arabidopsis transcription factors: genome-wide comparative analysis among eukaryotes. Science. 2000;15 (5499):2105-2110. doi: 10.1126/science.290.5499.2105

14. Uno Y, Furihata T, Abe H, Yoshida R, Shinozaki K, Yamaguchi-Shinozaki K. Arabidopsis basic leucine zipper transcription factors involved in an abscisic acid-dependent signal transduction pathway under drought and high-salinity conditions. Proc Nat Acad Sci U S A. 2000;97 (21):1163211637. doi: 10.1073/pnas. 190309197

15. Kobayashi F, Maeta E, Terashima A, Kawaura K, Ogihara Y, Takumi S. Development of abiotic stress tolerance via bZIPtype transcription factor LIP19 in common wheat. $J$ Exp Bot. 2008;59 (4):891-905. doi: 10.1093/jxb/ern014

16. Nijhawan A, Jain M, Tyagi AK, Khurana JP. Genomic survey and gene expression analysis of the basic leucine zipper transcription factor family in rice. Plant Physiol.2008;146:333-350. doi: 10.1104/pp.107.112821

17. Corre^a LGG, O-Pacho'n DMR, Schrago CG, Santos RVd, Mueller-Roeber B, Vincentz M. The role of bZIP transcription factors in green plant evolution: adaptive features emerging from fourfounder genes. PLOS ONE. 2008;3 (8):e2944. doi: 10.1371/journal.pone.0002944

18. Huang XS, Liu JH, Chen XJ. Overexpression of PtrABF gene, a bZIP transcription factor isolated from Poncirus trifoliata, enhances dehydration and drought tolerance in tobacco via scavenging ROS and modulating expression of stress-responsive genes. BMC Plant Biol.2010;10:230. doi: 10.1186/1471-2229$10-230$

19. Chen W, Provart NJ, Glazebrook J, Katagiri F, Chang H-S, Eulgem T, et al. Expression profile matrix of arabidopsis transcription factor genes suggests their putative functions in response to environmental stresses. Plant Cell. 2002;14:559574. doi: $10.1105 /$ tpc. 010410

20. Baloglu MC, Eldem V, Hajyzadeh M, Unver T. Genome-wide analysis of the bZIP transcription factors in cucumber. PLOS ONE. 2014;9 (4):e96014. doi: 10.1371/journal.pone.0096014

21. Liu X, Chu Z. Genome-wide evolutionary characterization and analysis of bZIP transcription factors and their expression profiles in response to multiple abiotic stresses in Brachypodium distachyon. BMC Genom.2015;16:227. doi: 10.1186/s12864015-1457-9

22. Rodriguez-Uribe L, O'Connell MA. A root-specific bZIP transcription factor is responsive to water deficit stress in tepary bean (Phaseolus acutifolius) and common bean (P. vulgaris). $J$ Exp Bot. 2006;57 (6):1391-1398. doi: 10.1093/jxb/erj118

23. Czechowski T, Bari RP, Stitt M, Scheible WR, Udvardi MK. Real-time RT-PCR profiling of over 1400 Arabidopsis transcription factors: unprecedented sensitivity reveals novel root- and shoot-specific genes. Plant J.2004;38(2):366-379. doi: 10.1111/j.1365-313X.2004.02051.x

24. Jamieson GS, Baughman WF. The chemical composition of sunflower-seed oil. J Am Chem Soc.1922;44 (12):2952-7. doi: 10.1021/ja01433a036

25. Nezamia A, Khazaeia HR, Rezazadehb ZB, Hosseini A. Effects of drought stress and defoliation on sunflower (Helianthus annuus) in controlled conditions. DESERT. 2008;12:99-104

26. Haseeb M, Maqbool N. Influence of foliar applied nitrogen on reproductive growth of sunflower (Helianthus annuus L.) under water stress. Agric Sci.2015;6:1413-1420. doi: 10.4236/ as.2015.612137

27. Staton SE, Bakken BH, Blackman BK, Chapman MA, Kane $\mathrm{NC}$, Tang S, et al. The sunflower (Helianthus annuus L.) genome reflects a recent history of biased accumulation of transposable elements. Plant J.2012;72 (1):142-153. doi: 10.1111/j.1365313X.2012.05072.x

28. Giordani T, Cavallini A, Natali L. The repetitive component of the sunflower genome. Curr Plant Biol.2014;1:45-54. doi: 10.1016/j.cpb.2014.05.001.9iuui80o

29. Pegadaraju V, Nipper R, Hulke B, Qi L, Schultz Q. De novo sequencing of sunflower genome for SNP discovery using RAD (Restriction site Associated DNA) approach. BMC Genom.2013;14:556. doi: 10.1186/1471-2164-14-556

30. Daneshian J. Response of sunflower lines to drought stress. Seed and Plant Improvement Research Institute; 2016. Personal communications.

31. 31. Michel BE, Kaufmann MR. The osmotic potential of polyethylene glycol 6000. Plant Physiol.1973;51 (5):914-916. doi: $10.1104 /$ pp.51.5.914

32. Livak KJ, Schmittgen TD. Analysis of relative gene expression data using real-time quantitative PCR and the $2^{-\Delta \Delta C \mathrm{CT}}$ method. Methods. 2001;25:402-408. doi: 10.1006/meth.2001.1262

33. Altschul SF, Gish W, Miller W, Myers EW, Lipman DJ. Basic local alignment search tool. J Mol Biol. 1990;215(3):403-410. doi: 10.1016/S0022-2836(05)80360-2

34. Fernandez P, Rienzo JAD, Moschen S, Dosio GA, Aguirrezábal LA, Hopp HE, et al. Comparison of predictive methods and biological validation for qPCR reference genes in sunflower leaf senescence transcript analysis. Plant Cell Rep.2011;30 (1):63-73. doi: 10.1007/s00299-010-0944-3

35. Bajić D, Poyatos JF. Balancing noise and plasticity in eukaryotic gene expression. BMC Genom.2012;13:343. doi: 10.1186/14712164-13-343

36. Weele CMVD, Spollen WG, Sharp RE, Baskin TI. Growth of Arabidopsis thaliana seedlings under water deficiet studied by control of water potential in nutrient-agar media. $J$ Exp Bot.2000;51(350):1554-1562. doi: 10.1093/jexbot/51.350.1555

37. Bartels D, Sunkar R. Drought and salt tolerance in plants. Crit Rev Plant Sci.2005;24(1):23-58. doi: 10.1080/07352680590910410

38. Ingram J, Bartels D. The molecular bases for dehydration tolerance in plants. Ann Rev Plant Physiol Plant Mol Biol.1996;47:377-403. doi: 10.1146/annurev.arplant.47.1.37

39. West G, Inzé D, Beemster GTS. Cell cycle modulation in the response of the primary root of Arabidopsis to salt stress. Plant Physiol .2004;135(2):1050-1058. doi: 10.1104/pp.104.040022

40. Yoshiba Y, Kiyosue T, Nakashima K, YamaguchiShinozaki K, Shinozaki K. Regulation of levels of proline as an osmolyte in plants under water stress. Plant Cell Physiol.1997;38(10):1095-1102

41. Valliyodan B, Nguyen HT. Understanding regulatory networks and engineering for enhanced drought tolerance in plants. Curr Opin Plant Biol.2006;9 (2):189-195. doi: 10.1016/j. pbi.2006.01.019

42. Hare PD, Cress WA, Staden JV. Dissecting the roles of osmolyte accumulation during stress. Plant Cell Environ. 1998;21(6):535553. doi: 10.1046/j.1365-3040.1998.00309.x

43. Serraj R, Sinclair TR. Osmolyte accumulation: can it really help 
increase crop yield under drought conditions? Plant Cell Environ. 2002;25:333-3341. doi: 10.1046/j.1365-3040.2002.00754.x

44. Caldana C, Scheible W-R, Mueller-Roeber B, Ruzicic S. A quantitative RT-PCR platform for high-throughput expression profiling of 2500 rice transcription factors. Plant Methods. 2007;3:7. doi: 10.1186/1746-4811-3-7

45. Balazadeh S, O-Pacho'n DMR, Mueller-Roeber B. Transcription factors regulating leaf senescence in Arabidopsis thaliana. Plant Biol.2008;10(Suppl. 1):63-75. doi: 10.1111/j.14388677.2008.00088.x

46. Matsumoto T, Wu J, Kanamori H, Katayose Y, Fujisawa M, Namiki N, et al. The map-based sequence of the rice genome. Natre. 2004;436:793-800. doi: 10.1038/nature03895

47. Kaul S, Koo HL, Jenkins J, Rizzo M, Rooney T, Tallon LJ, et al. Analysis of the genome sequence of the flowering plant Arabidopsis thaliana. Nature. 2000;408:796-815. doi: $10.1038 / 35048692$
48. Fowler S, Thomashow MF. Arabidopsis transcriptome profiling indicates that multiple regulatory pathways are activated during cold acclimation in addition to the CBF cold response pathway. Plant Cell. 2002;14 (8):1675-1690. doi: 10.1105/tpc.003483

49. Rabbani MA, Maruyama K, Abe H, Khan MA, Katsura K, Ito $\mathrm{Y}$, et al. Monitoring expression profiles of rice genes under cold, drought, and high-salinity stresses and abscisic acid application using cDNA microarray and RNA gel-blot analyses. Plant Physiol. 2003;133(4):1755-1767. doi: 10.1104/pp.103.025742

50. Everett L, Hansen M, Hannenhalli S. Regulating the regulators: modulators of transcription factor activity. Methods Mol Biol. 2010;673:297-312. doi: 10.1007/978-1-60761-854-6_19

51. Chen W, Provart NJ, Glazebrook J, Katagiri F, Chang HS, Eulgem T, et al. Expression profile matrix of Arabidopsis transcription factor genes suggests their putative functions in response to environmental stresses. Plant Cell. 2002 ;14(3):559574. doi: $10.1105 /$ tpc. 010410 